\title{
Riscos sociais e as motivações dos territórios intencionalmente de risco: percepções sobre o rio de janeiro e o distrito federal
}

\section{Social risks and the motivations of intentionally risky territories: perceptions on rio de janeiro and the federal district}

\author{
DOI: $10.46814 /$ lajdv3n2-008
}

Recebimento dos originais: 23/12/2020

Aceitação para publicação: 26/02/2021

\author{
Ma. Érica Ferrer \\ Estudante de Doutorado em Geografia na Universidade de Brasília-UNB \\ Campus Universitário Darcy Ribeiro Universidade de Brasília- UnB Departamento de Geografia \\ GEA ICC Norte 900 - Brasília, DF - Brasil \\ E-mail: ericaferrergeografia@gmail.com
}

\section{RESUMO}

A criminalidade e a insegurança são uma grande preocupação sentida nas cidades. Tal medo tem sido manipulado por empresas de segurança pública, lançamentos imobiliários e programas de governo para gerar lucro e votos. No entanto, tal insegurança coletiva deve ser trazida para o meio científico para que sejam estudados quais fatores causam o aumento do índice de homicídios, por exemplo. A falta de infraestrutura neste estudo se mostra como um causador desse aumento, porém o governo tem esse conhecimento e, em muitos casos, não o aplica. Assim, o conceito do território intencionalmente de risco visa propor uma reflexão acerca desse descaso governamental em certas áreas e o grande investimento em infraestrutura em outras regiões. Ainda, aborda as motivações que podem levar o governo a não direcionar políticas públicas em determinados territórios com risco social. Neste estudo são utilizados três bairros da cidade do Rio de Janeiro e três regiões administrativas do Distrito Federal.

Palavras-chave: território intencionalmente de risco, criminalidade, infraestrutura.

\begin{abstract}
Crime and insecurity are a major concern felt in cities. Such fear has been manipulated by public security companies, real estate projects and government programs to generate profit and votes. However, such collective insecurity should be brought into the scientific environment in order to study which factors cause the increase in the homicide rate, for example. The lack of infrastructure in this study is shown as a cause of this increase, but the government has this knowledge and, in many cases, does not apply it. Thus, the concept of intentionally risky territory aims to propose a reflection about this governmental neglect in certain areas and the large investment in infrastructure in other regions. It also addresses the motivations that may lead the government not to direct public policies in certain territories with social risk. In this study three neighborhoods of the city of Rio de Janeiro and three administrative regions of the Federal District are used.
\end{abstract}

Keywords: intentionally risky territory, criminality, infrastructure. 


\section{INTRODUÇÃO}

A violência é um problema muito discutido quando se debate sobre a gestão das cidades. No entanto, muitas vezes a segurança acaba sendo o ponto central discutido nos projetos de cidade. Mas será que colocar o tema da segurança pública em primeiro lugar pode estar relegando problema estruturais urbanos como a desigualdade social em último plano? Por que o governo (que sabe que a infraestrutura diminui os índices de criminalidade dos homicídios) não distribui a infraestrutura de forma menos desigual nos territórios?

Essas questões serão debatidas ao longo deste artigo de forma a esclarecer a problemática. Assim, serão expostos o ponto de vista histórico, a opção por um tipo específico de segurança e os dados que comprovam tal associação entre infraestrutura e criminalidade dos homicídios.

\section{OS RISCOS SOCIAIS E O TERRITÓRIO INTENCIONALMENTE DE RISCO}

O Rio de Janeiro tem um projeto de segurança pública voltado para o turismo e para a elite. Assim, bairros da zona sul, como o Leblon são priorizados no investimento público possuindo tanto melhor infraestrutura quanto mais equipamentos de segurança pública. A cidade optou pelo turismo e pela atração de grandes eventos para aquecer sua economia, pois necessitou se refuncionalizar após a perda da função econômica para São Paulo e da centralidade política para Brasília. Desta forma, várias obras e projetos têm sido realizados para criar um ambiente voltado para os turistas, tais como: o Rio sem homofobia (projeto estatal), a Transcarioca, as intervenções urbanísticas nas favelas, as obras no Maracanã, o projeto Porto Maravilha e as UPPs (Unidades de Polícia Pacificadora). Por outro lado, os subúrbios e favelas que estão distanciados do turismo não possuem tanto investimento de infraestrutura, como Madureira e Santa Cruz.

No Distrito Federal, a segurança pública tem um viés tanto de proteger a elite quanto tem um caráter político/estratégico de controle, principalmente na região administrativa de Brasília. Nesta região estão as sedes dos poderes nacionais (legislativo, jurídico e executivo), como o Palácio do Planalto, o Supremo Tribunal Federal, o Senado Federal etc. A região administrativa de Brasília é tanto urbanisticamente quanto policialmente controlada de forma mais efetiva do que as outras regiões do Distrito Federal. Ainda é na região administrativa de Brasília que está a presença maior de funcionários públicos e de população com maior renda. Em outras regiões administrativas como Ceilândia e Taguatinga, tanto a segurança quanto a presença de uma população com maior renda não é tão observada.

Em ambas realidades a infraestrutura acaba sendo menos presente em territórios de populações mais pobres o que acaba por geram maiores índices de criminalidade de homicídios como pode ser observado nas Tabelas I, II, III e IV. 
Tabela I. Média anual de homicídios por 100 mil habitantes no Rio de Janeiro no ano de 2013 por AISP

\begin{tabular}{|c|}
$\begin{array}{c}\text { (AISP 23) } \\
\text { Leblon, }\end{array}$ \\
$\begin{array}{c}\text { Rocinha, Ipanema, Gávea, Jardim Botânico, Lagoa, São Conrado e Vidigal } \\
\text { Média de 5,4 homicídios }\end{array}$ \\
$\begin{array}{c}\text { (AISP 27) } \\
\text { Santa Cruz, }\end{array}$ \\
Paciência, Guaratiba, Pedra de Guaratiba e Sepetiba \\
Média de 37,92 homicídios \\
\hline $\begin{array}{c}\text { (AISP 9) } \\
\text { Madureira, }\end{array}$ \\
$\begin{array}{c}\text { Campinho, Cascadura, Praça Seca, Quintino Bocaiúva, Vila Valqueire, Cavalcanti, Engenheiro } \\
\text { Leal, Madureira, Turiaçu, Vaz Lobo, Bento Ribeiro, Marechal Hermes, Oswaldo Cruz Coelho } \\
\text { Neto, Colégio (Parte), Honório Gurgel e Rocha Miranda } \\
\text { Média de 32,4 homicídios }\end{array}$ \\
\hline
\end{tabular}

Fonte: Elaboração própria a partir de dados da Secretaria de Estado de Segurança do Rio de Janeiro, 2014.

Tabela II. Média anual de homicídios por 100 mil habitantes no ano de 2013

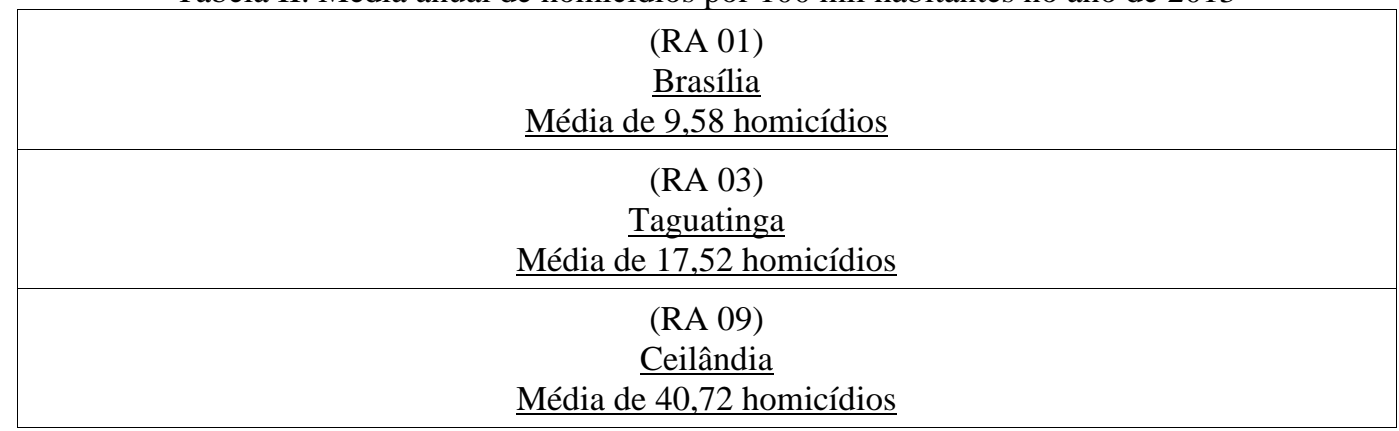

Fonte: Elaboração própria a partir de dados da Secretaria de Estado de Segurança Pública do Distrito Federal, 2014.

Tabela III. Infraestrutura na cidade do Rio de Janeiro

\begin{tabular}{|c|c|c|c|}
\hline & Leblon & Madureira & Santa Cruz \\
\hline População & 46.044 & 50.106 & 217.333 \\
\hline Hospitais públicos & 1 & 1 & 1 \\
\hline Delegacias & 3 & 1 & 0 \\
\hline Teatros & 6 & 4 & 3 \\
\hline Livrarias & 10 & 0,831 & 0,742 \\
\hline IDH & 0,967 & 980,13 & 509,71 \\
\hline Renda per Capita & $5.805,42$ & 18 & 92 \\
\hline $\begin{array}{c}\text { Escolas e creches } \\
\text { públicas }\end{array}$ & 3 & & \\
\hline
\end{tabular}

Fonte: Elaboração própria a partir de dados do Instituto Municipal Pereira Passos, Secretaria de Estado de Educação do RJ, Secretaria Municipal de Educação do RJ, Polícia Civil do RJ, Lista telefônica do RJ, 2014.

Tabela IV. Infraestrutura no Distrito Federal

\begin{tabular}{|c|c|c|c|}
\hline & Brasília (RA 01) & Taguatinga (RA 03) & Ceilândia (RA 09) \\
\hline População & 208.666 & 199.715 & 402.729 \\
\hline Hospitais públicos & 6 & 2 & 1 \\
\hline Delegacias & 9 & 4 & 4 \\
\hline
\end{tabular}




\begin{tabular}{|c|c|c|c|}
\hline Teatros & 8 & 1 & 1 \\
\hline Livrarias & 70 & 16 & 5 \\
\hline IDH & 0,936 & 0,855 & 0,784 \\
\hline Renda per capita & $3.835,27$ & $1.318,38$ & 611,29 \\
\hline $\begin{array}{c}\text { Escolas e creches } \\
\text { públicas }\end{array}$ & 85 & 55 & 89 \\
\hline
\end{tabular}

Fonte: Elaboração própria a partir de dados da Codeplan, Seplan, Secretaria de Educação do DF, Secretaria de Saúde do DF, Polícia Civil do DF, Lista telefônica, Jornal Correio Braziliense, 2014.

Neste ponto, a geografia pode oferecer uma análise do fenômeno. García-Tornel pode explicar tal realidade através do sentido novo que dá para vulnerabilidade social sendo esta "a expressão do desequilíbrio ou desajuste entre a estrutura social e o meio físico, construtivo e natural que nos rodeia, de maneira que aparece como um conceito multidimensional que engloba simultaneamente fatores físicos e sociais e que ao mesmo tempo depende em linhas gerais, do tipo de intensidade da ameaça. Em consequência não tem valor absoluto" (GARCÍA-TORNEL, 2001, p. 108). Neste conceito o autor consegue inclusive unir geografia física e humana ao propor uma análise que toca mais a totalidade.

O mesmo autor afirma que "os territórios de risco vêm determinados por aquelas regiões planetárias onde o fato de ocorrer determinados fenômenos físicos ou biológicos, ou a presença de instalações perigosas são mais frequentes, de maneira que os riscos maiores têm espaços concretos, mais ou menos extensos, onde se manifestam preferentemente e aos que temos aludido para nos referir as suas características" (GARCÍA-TORNEL, 2001, p. 124). Tal conceito é aplicável neste artigo pois não seria só a "presença de instalações perigosas" que determinariam o território de risco, mas também a falta de "instalações seguras" (como a infraestrutura). Ainda, muitos desses espaços são criados de forma intencional (tanto a ação quanto a omissão do Estado são intenções). Dessa forma, que nasce o conceito de território intencionalmente de risco.

Assim, o território intencionalmente de risco seria aquele onde o governo não equipa o território com a infraestrutura necessária para aquela sociedade. As consequências seriam a criminalidade, a menor escolaridade, a desnutrição, a maior incidência de doenças etc.

\section{AS MOTIVAÇÕES DO TERRITÓRIO INTENCIONALMENTE DE RISCO}

A ação e a omissão da decisão política refletem no espaço criando territórios intencionalmente de segurança e territórios intencionalmente de risco. Assim, surge a questão sobre qual seria a motivação para que sejam criados territórios intencionalmente de riscos.

Uma das motivações poderia ser a própria preferência em investir mais dinheiro público nos locais onde os moradores com maior força política (prefeitos, deputados, governadores, donos de 
grandes empresas, juízes) residem, pois muitos desses moradores que de fato escolhem (ou influenciam) onde investir o dinheiro público.

A questão imobiliária pode ser também uma motivação, pois manter certas áreas desvalorizadas (também por serem "territórios de risco") mantém reservas territoriais que podem ser exploradas futuramente.

A indústria do medo também se beneficia desses territórios através de empresas de segurança, indústria armamentista, presídios e condomínios fechados (cada vez mais disseminados nas cidades).

Os fins eleitoreiros também são beneficiados, pois alguns candidatos políticos tem por pauta governamental apenas a questão da polícia intensiva nas ruas, de criminalizar ainda mais setores hipossuficientes da população (como os mais pobres que não têm acesso ao direito de se defenderem de forma efetiva).

\section{CONCLUSÃO}

Ao se discutir segurança pública é necessário observar que existe uma intencionalidade em manter certos territórios mais seguros que outros.

Logo, a responsabilidade existe quando a decisão política se omite nos espaços de população mais pobre e age nos espaços de população mais rica (ou nos territórios onde tem motivação econômica). Por isso, Estado deve se responsabilizar pelas consequências decorrentes dessa omissão. Ou seja, altos índices de homicídios em certos territórios são responsabilidade direta do Estado.

Assim, é necessário buscar formas mais efetivas de responsabilizar e fiscalizar o investimento público nos territórios para que tanto a desigualdade territorial quanto a insegurança pública em territórios dos mais pobres (ou o analfabetismo, a incidência de doenças, a mortalidade infantil) sejam diminuídas. 


\section{BIBLIOGRAFIA}

Farias, J. (2006) - Cidades Negras: africanos, crioulos e espaços suburbanos no Brasil escravista do século XIX. São Paulo, Ed. Alameda, 174 p.

Fernandes, A. (2012) - Processo Penal Institucional. São Paulo. Editora Revista dos Tribunais, 348 p.

Foucault, Michel (1987) - Vigiar e punir: nascimento da prisão. Petrópolis, Editora Vozes, 262 p.

García-Tornel, Francisco (1997) - Algunas cuestiones sobre Geografía de los Riesgos. Scripta Nova: Revista Electrónica de Geografía y Ciencias Sociales, Vol. I, n. 10, p. 1-5.

Gross, P. (1998) - Ordenamento Territorial: El manejo de los espacios rurales. Latinoamericana de Estudios Urbano Regionales, Vol XXIV, n. 73, p. 116-118.

Santos, M. (2012) - A natureza do Espaço. Técnica e tempo. Razão e emoção. São Paulo, EDUSP, 392 p. 